\title{
O FIM DO COLONIALISMO EM ANGOLA E A TESSITURA DA NARRATIVA- NAÇÃO, SOB O OLHAR DE PEPETELA
}

\author{
Maria Geralda de Miranda
}

(UNISUAM)

\begin{abstract}
RESUMO
O romance Yaka, do escritor angolano Pepetela, se estrutura em cinco segmentos: "A boca - 1890/1904", "Os olhos - 1917", “O coração - 1940/1941", "O sexo - 1961" e "As pernas - 1975". Cada um deles, além de corresponder a uma geração da família Semedo, cuja trajetória se inicia com o degredo de Oscar, português, e termina com Joel, tetraneto de Oscar, atuando nas fileiras do MPLA, corresponde também a um determinado tempo histórico, marcado pela deflagração de conflitos bélicos e pelo acirramento da luta entre colonizador e colonizado. A saga dos Semedo, apesar de ser ficionalizada apenas como a trajetória de uma família de colonos portugueses radicada em Angola, ganha, no decorrer da narrativa, um significado amplo, por causa justamente de sua imbricação com as guerras e com toda a problemática da ocupação colonial. O presente trabalho buscará mostrar que esse processo de reconstituição do passado, através da ficção, implica, entre outras coisas, a transcodificação da matéria historiográfica que - ao passar pela pena do ficcionista ou, se preferirmos, ao passar pelo filtro do texto literário - sofre várias alterações. Os eventos narrativos relatados no romance são fios da história angolana artisticamente retecidos por Pepetela, que com "engenho e arte" reelabora e, ao mesmo tempo, tece a sua "narrativa-nação".
\end{abstract}

PALAVRAS-CHAVE: Pepetela; Yaka; colonialismo; nação.

\section{ABSTRACT}

The novel Yaka, written by the angolan writer Pepetela, is structured in five segments: "The mouth - 1890-/1904", “The eyes -1917”, “The heart-1940/1941", “The sex-1961”, and "The legs-1975”. Each segment corresponds to a generation of the Semedo's family whose journey begins with the banishment of Oscar, Portuguese, and ends with Joel, Oscar's greatgrandchild as a member of the MPLA ranks; this is also related to a certain historical time characterized by the beginning of the military conflicts and the stirring up of the fight between the colonizer and those who were being colonized. Despite being labeled in fiction as a story of a portuguese family 
of settlers settled in Angola, the Semedo's saga reaches during its narrative, a wide meaning due to its intrinsic connection with the wars and with all the problems originated as a result of the colonization. The present work aims to show that all this process of rebuilding the past, through fiction, has to do , among other things, with the transcodification of the historiographic context that- the moment it goes through the fiction writer's ink or, if we prefer, goes through the literary text screen - suffers many changes. The narrative events described in the novel are threads in the Angolan history rewoven majestically by Pepetela, who with "skill and talent" reorganizes and, at the same time, weaves his "tale-nation"

KEYWORDS: Pepetela; Yaka; colonialism; Angolan-related subjects.

\title{
CONSIDERAÇÕES INICIAIS
}

\begin{abstract}
Esperava a chuva única, talvez sem água, que ia ligar a boca aos olhos e às pernas e ao sexo, ainda isolados em desconfianços. Se cumpriria então o augúrio lido nos intestinos do cabrito, que confundia ruído de chuva com música estranha, nova, mas tão nossa?
\end{abstract}

(Pepetela, 1985, p. 14)

Nascida do embate anticolonial e não da luta contra o feudalismo (como os estados-nação da Europa, onde a burguesia foi o principal agente de construção nacional), a nação angolana, tal como hoje se apresenta, começou a delinear com mais nitidez os seus contornos territoriais a partir do final do século passado, quando, exatamente, se inicia, no plano da ficção, no romance Yaka, a trajetória da família Semedo em Angola. Antes desse período, a relação do governo metropolitano com a aludida colônia se dava em bases puramente mercantilistas e não através de uma política de povoamento.

Foram as intensas campanhas militares de ocupação do interior do país, no final do século XIX, e o assentamento de brancos nas áreas ocupadas, que, de fato, fizeram Angola mudar o seu perfil. O desenvolvimento do comércio e da agricultura levou à ampliação das cidades e a implantação de escolas contribuiu, ainda que lentamente, para a formação de uma elite mestiça bilíngue. A administração centralizada que, em certa medida, submetia os grupos pluriétnicos às mesmas leis, à mesma língua e à mesma bandeira, e também o território comum conferiam à referida colônia um aspecto de unificação.

Sobre a questão das fronteiras - que é um dado importante quando se pensa as nações modernas e, principalmente, quando se pensa as nações surgidas da descolonização, já que, segundo Eric Hobsbawn (1991, p. 166), "os nacionalismos resultantes dessas últimas se alicerçam em bases territoriais", e não em bases étnicas ou de consciências de cidadania - vale dizer, que as de Angola foram traçadas pelo poder bélico dos dominadores, a partir de 1890. 
Este é, aliás, um ano de plurissignificação no romance Yaka, objeto deste trabalho, não só porque nele nasce Alexandre (narrador e protagonista e o primeiro Semedo nascido em Angola), mas porque acontece também o Ultimatum Inglês. Este último fato se relaciona diretamente com a revolta do Bié (também ocorrida em 1890, data inicial do primeiro segmento da obra em estudo) que em muito contribuiu para a intensificação dos conflitos bélicos em Angola, pois levou Portugal a ocupar, com radicalidade, o sertão angolano.

A conferência de Berlim, realizada em 1885, já havia limitado drasticamente os atos de soberania portuguesa sobre as terras africanas, pois, durante a sua realização, foi acordado que o direito às mencionadas terras "deveria provar-se pela posse presente, atestada por guarnições de soldados e não por argumentos históricos” (SARAIVA, 1987, p. 341), invocados durante séculos por portugueses. O Ultimatum Inglês veio a ser um elemento deflagrador de uma profunda crise no governo luso que, para lavar a honra nacional, manchada pela imposição inglesa, acabou invadindo e submetendo as regiões do o Bié e do Bailundo.

Sobre a Conferência de Berlim, é notório que em seu decorrer não foi assinado nenhum tratado de partilha da África entre as potências presentes, mas a especificação de regras de ocupação levou a uma tumultuosa corrida, ocasionando, na prática, a tão cobiçada partilha do continente. Assim, conforme Pélissier (1986, v1, p. 208), em 1885, houve um acordo entre "Portugal e a Associação Internacional do Congo, nos termos do qual o primeiro renunciava à margem direita do Zaire, conservando apenas o enclave de Cabinda; em 1886, a Convenção Franco-Portuguesa delimitava os respectivos territórios da Guiné e de Cabinda". Contudo, um dos artigos dessa convenção reconhecia a soberania de Portugal sobre os territórios compreendidos entre Angola e Moçambique "um mapa anexado à convenção por Portugal, mostrava a cor-de-rosa as regiões que ele reivindicava." (PÉLISSIER, 1986, v. 1, p. 209).

Nesse mesmo ano teve lugar o Acordo Luso-Alemão que definiu a fronteira meridional de Angola. Os portugueses renunciavam ao Cabo Frio e ficavam com o Cunene como limite costeiro de suas possessões, em troca do reconhecimento pela Alemanha de seu direito de ocupação dos territórios do "mapa cor-de-rosa. O problema é que os ingleses não concordavam com as convenções assinadas entre Portugal e os outros países, e protestaram. A Área colorida incluía, dizia o protesto, "regiões em que a Inglaterra tem um interesse excepcional”, (SARAIVA, 1987, p. 342). Estas regiões são aproximadamente as que formam hoje a Rodésia e a Zâmbia.

Para dizer as palavras certas, após a Conferência de Berlim, toda a Europa declarou guerra à África, pois cada um dos protagonistas do imperialismo, no ímpeto de ocupar os territórios resultantes da partilha, tiveram de implantar-se de arma na mão. O agravante, no caso português, é que as autoridades lusas nem bem puseram em prática as deliberações da Conferência (através do plano de ocupação dos territórios do "mapa cor-de-rosa") e tiveram que recuar. A marcha que objetivava a ocupação da Baratselântica (a partir do Bié) foi reduzida a uma simples expedição geográfica ao Cubango. 
A luta de libertação nacional, iniciada em 1961, como diz Pélissier (1986, v. 2, p. 19), era "o resultado de uma longa série de guerras", ocasionadas quase sempre pela insubordinação dos vários povos localizadas no território denominado angolano contra os conquistadores. Era também a prova incontestável de que sempre houve resistência à opressão colonial. Principalmente depois de 1941, em várias ocasiões, as autoridades portuguesas afirmaram que a situação em Angola estava totalmente sob controle. A bem da verdade, em 1961, as terras já se encontravam todas conquistadas; as fronteiras já estavam devidamente delineadas e a maioria dos grupos étnicos já se havia dispersado. Mas, como diz Pepetela, em sua linguagem simbólica, "a chuva de música chegou." (PEPETELA, 1985, p. 205).

A saga dos Semedo, apesar de ser ficcionalizada apenas como a trajetória de uma família de colonos portugueses radicada em Angola, ganha, no decorrer da narrativa, um significado amplo, por causa justamente de sua imbricação com as guerras e com toda a problemática colonial. $\mathrm{Na}$ verdade, é através do ato de contar essa trajetória particular que Pepetela, como diria Homi Bhabha $(1995$, p. 9) se lança "ao laborioso ato de falar da própria coletividade". Nesse sentido, a saga da família pode ser lida como uma alegoria da própria formação da nacionalidade, já que funciona como motivo e meio pelos quais se conta a história nacional.

\section{NAÇÃO-CORPO-NARRAÇÃO}

As nações, como as narrativas, perdem suas origens nos mitos do tempo." (BABHA, 1995, p. 7).

Em ensaio sobre o romance Yaka, Alexandre Pinheiro Torres (1987, p. 97) se refere à segmentação da obra do seguinte modo: "Penso que Pepetela divide o seu romance em cinco partes, "A boca", "Os olhos", "O coração", "O sexo" e "As pernas", porque talvez tenha julgado que é através dessas vias que os colonos e conquistadores dão o flanco". E segue dizendo que começa realmente pela boca a avidez da ganância, "de encher a bolsa e barriga, por meio de uma exploração de recursos naturais que vão desde os 'escravos' que se transacionam até os couros, uma série de ciclos econômicos, onde cada um (borracha, marfim ou cera) não deixa menos traumatismo que os outros." (TORRES 1987, p. 97).

A nossa leitura da estrutura segmentada e/ou fragmentada de Yaka, assim como a leitura de seus títulos não é a mesma proposta pelo ensaísta citado. Penso até que sua interpretação reduz bastante o alcance simbólico da narrativa que, em seu conjunto, possui mesmo um sentido de "narrativa-nação". É evidente que as questões econômicas se fazem presentes no texto: foram a concorrência desleal e a baixa do preço da borracha que levaram os bailundos a se revoltarem em 1902; foram as terras boas para o café, que os colonizadores iam abocanhando, que levaram sumbes e seles ao levante de 1917; foram também os bois e as terras, a leste de Moçâmedes, que levaram os cuvales à guerra de 1940/41. (As guerras contra o Cuamato e o Bié, respectivamente em 1890 e 1904, foram decorrência direta da ocupação dessas regiões pelos colonizadores).

Torres, mesmo fazendo uma leitura "economicista", digamos assim, da segmentação da obra, só citou, na verdade, as atividades econômicas relativas ao primeiro segmento, o que torna ainda mais difícil ler a obra 
por essa via. Para se ler a nação, como está tecida em Yaka, faz-se necessário verificar a relação existente entre os títulos e as datas - bem como as lutas narradas - com o evento relatado na parte final do romance, denominado revolução. No segmento “A boca - 1890/1904", o Bié, o Bailundo e o Cuamato dizem não a Portugal. É o primeiro passo para a construção dessa nação-corpo-narração.

Pela "boca", a nação "fala" pela primeira vez. E tanto é assim que do mesmo segmento também ecoa o primeiro vagido de Alexandre Semedo, que mordeu a terra angolana ao nascer, estabelecendo com ela o seu compromisso. A estátua Yaka, que dá nome à obra e que também assume posição de personagem e narradora em vários momentos do texto, diz ser a "mordidela-beijo" (PEPETELA, 1985, p.14) do menino que vai puxar a "chuva de música", metáfora da revolução. Essa referida personagem-narradora que viu Alexandre nascer porque estava em cima do carro bôer, "amarrada junto às imbambas" (PEPETELA, 1985, p. 22), é quem faz a articulação simbólica dos eventos de 1890/1904 com o evento de 1975, através da metáfora "chuva de música". Tal metáfora, aliás, liga todos os eventos relatados nos outros segmentos à revolução. Observemos primeiramente a articulação simbólica dos acontecimentos de 1961 com os de 1975.

Os intestinos do cabrito abertos e sanguinolentos escreviam, a chuva de música chegou. Os fumos brancos das penas de capota queimadas apontavam a chuva. E chuva choveu? Chuviscou só orvalhos nas hastes de capim (...) orvalhos nas ruas de Luanda, da Casa de Reclusão. Mas a chuva de lavar a terra vermelha, a chuva de torrentes barrentas levando casas, carros e gentes para o mar, a música limpadora de rancores e de medos, a chuva estava aonde?"(PEPETELA, 1985, p. 205).

O inicio da luta armada se faz representar pelos "chuviscos e orvalhos", mas a narradora tem tal urgência da chuva de "torrentes barrentas" (acontecida em 1975 e que, de fato, levou centenas e centenas de portugueses a deixarem Luanda, levando todos os seus bens) que chega até mesmo a pensar, quando vê apenas chuviscos e orvalhos, que os intestinos do cabrito e as penas da capota se haviam enganado. E pergunta:

O cabrito se enganou nos seus enrolados intestinos? Não pode. As penas pretas (...) da capota se enganaram? Não pode. Os olhos dos sumbes e dos seles que se misturaram aos olhos dos cuvales sem gado traziam apenas gotas esparsas. No norte, muitos outros sumbes e cuvales tinham a mesma certeza de torrenciais trovoadas. (PEPETELA, 1985, p. 205-6, grifo meu)

Neste ponto há uma articulação mais ampla. A narradora traz para as cenas de 1961 e 1975 a luta dos seles e cuvales (acontecidas em 1917 e 1940/41) ligando respectivamente "Os olhos" e "O coração" aos segmentos: "O sexo" e "As pernas". Ao articular simbolicamente as datas, através de imagens de um mesmo campo semântico (a palavra chuva), a narradora coloca as lutas do povo autóctone (de 1890 a 1941) a serviço do evento de 1975. Trata-se, como diria Said (1995, p. 18), "de invocar o passado como estratégia de intervenção no presente". Este presente é o das "torrenciais trovoadas". O presente da revolução, meio pelo qual se realiza a nação em Angola. 
Os acontecimentos de 1975 são, no plano histórico e simbólico, desdobramentos dos fatos ocorridos em 1961, diferentemente dos eventos realizados entre 1890 e 1941, que só se relacionam com os acontecimentos de 1975 (com a revolução) no plano simbólico. No plano histórico, os protagonistas da revolução eram movimentos urbanos; a luta armada, iniciada pelo MPLA, era uma opção militar para resolver um problema político: a independência. As outras lutas tinham também, evidentemente, o seu caráter libertário, mas eram lutas isoladas, ou melhor, lutas que visavam liberar uma determinada região, pertencente a um determinado soba, mas não a nação angolana, enquanto "comunidade imaginada - e imaginada como implicitamente limitada e soberana” (ANDERSON, 1989, p. 14), utilizando aqui a útil definição de Benedict Anderson.

Só a revolta dos seles e amboins, de acordo com Pélissier (1986, v.2), parece ter tido um papel mais abrangente. O que une os acontecimentos ocorridos em 1961 aos ocorridos em 1975 é o projeto nacional ou nacionalizante. A consciência de angolanidade crescia nas cidades, de onde partiu a revolução. Nesse sentido, o ano de 1961 pode ser lido como o ano em que o colonizado perde a sua inocência e por isso deve ser considerado um marco na história nacional de Angola. É o ano da puberdade do colonizado, que deseja se afirmar enquanto ser nacional. Não é a toa que o segmento em que se conta o início da luta armada traz como título "O sexo".

A luta armada tem inicio no dia 4 de fevereiro de 1961, com o assalto de membros do MPLA à Casa de Reclusão. Nos dias 5 e 6 foram mortos em Angola entre 200 e 300 colonos portugueses, o que levou as autoridades colonialistas a matarem em Luanda cerca de 3.000 pessoas, criando um clima de insurreição armada em toda Angola. Além do levante do Norte (que são as notas musicais nortistas) os guerrilheiros do movimento de Agostinho Neto mantêm durante seis meses o território do Nambuagongo liberto do domínio colonial. Nesse mesmo ano, já em outubro, a sede do MPLA se estabelece em Leopoldville e, no dia 8, o Governador Geral de Angola declara em comunicado oficial: "A guerra de Angola acabou." (RAMOS, 1979, p. 386). Ela, na verdade, estava só começando. E era guerra de libertação nacional e não levante isolado como ocorrera em anos passados.

O ano de 1961 e o de 1975 são articulados simbólica e historicamente pelo MPLA (foi esse movimento armado que proporcionou a "chuva de música"). Tal movimento, diante do massacre e da repressão promovidos pelas autoridades coloniais, a partir do assalto às prisões de Luanda, embrenha-se nas matas dos Dembos e de Nambuagongo (onde organiza a sua primeira região militar), lá permanecendo até 1975. Com o Acordo de Alvor e com a data da independência marcada, imaginava-se que Portugal sairia da vida daquela quase nação "tranquilamente". Mas,

quando a paz mentirosa parecia enlanguecer os músculos e as vontades, estourou aquele trovão medonho que para muitos era música de marimba anunciando água fresquinha a cair gota a gota de cascatas intermináveis (...), para outros só foi isso mesmo um trovão medonho, de estarrecer, (...), mas já o trovão tinha chamado as nuvens grossas e os batuques refloresceram nos cânticos coletivos de bater palma, agora é que era (...), os homens importantes donos de impérios despertaram da letargia provocada pelo 
estupor do trovão, começando a se agitar em conciliábulos secretíssimos, criando partidos, movimentos, grupos que depois eram anunciados pelo rádio, todos falando no amor dos homens importantes pela terra portentosa, votada ao abandono antes mas agora, com eles, destina a ser um País florescente, porque eles até sempre quiseram, o Salazar e séquito é que não deixavam, nós amamos Angola como nossa."(PEPETELA, 1985, p. 245-46).

O problema é que as populações autóctones não acreditavam na palavra e nem nos partidos dos "donos dos impérios econômicos" formados em Angola. Muito pelo contrário, não queriam saber de eleição.

Os cuvales não ouviam nada dessas idéias e sonhos, queriam só saber onde estava a terra de quarenta e um, apesar de que, depois de dispersos, se dedicaram à agricultura todos, homens e mulheres, que se lixasse a tradição, e foram acumulando grão a grão o suficiente para comprar um boi aqui, uma vaca ali e ao fim (...) as manadas do antigamente e o seu orgulho de gente inconquistável, cactos sempre eretos no deserto, e os seles e os de lá do Norte não ouviam aquela rádio, perguntavam masé onde estão as terras boas para o café que agora viraram embora roça e roças, império no império (...) e as danças na rua da capital e o referendo estava feito, as eleições estavam feitas (...) o resto, partidos, grupos em vias de desmoronamento perante o gaudio das multidões."(PEPETELA, 1985, p. 245, grifo meu).

Aqui o narrador coloca abertamente, e não mais só através da metáfora da "chuva de música", as lutas dos povos autóctones a serviço da revolução, cabendo um destaque para os cuvales, comparados, em diversos momentos, a cactos pela sua firmeza, valentia e determinação. Tal povo se faz presente em mais de uma etapa de construção da nação-narração de Pepetela. Contudo o maior destaque se dá no terceiro segmento "O coração" onde se narra a guerra de 1940/41. Alexandre Semedo nasce e se batiza em terra cuvale; Joel/Ulisses, bisneto de Alexandre Semedo e guerrilheiro do MPLA, juntamente com o "povo cacto", preparou a estratégia para ocupar Benguela - metáfora de Angola - deixando-a livre daqueles que a queriam dividir.

No fragmento acima, o narrador informa que o povo cuvale continuava com "o seu orgulho de gente inconquistável", apesar da dispersão ocorrida após a guerra de 1940/41. Os cuvales são "O coração" de Yaka, a sua força motriz. Podemos observar que nesse corpo, que se vai formando a partir dos títulos - ou nesse romance que sei vai fazendo a partir dos segmentos -, não aparece o cérebro. "O coração" funciona como o cérebro. Os cuvales são o cérebro da efabulação de Yaka.

Os cuvales nunca foram conquistados, portanto, não possuíam corações escravos. Eram "cactos", daí serem convocados para o evento de 1975, para desferirem o golpe final nos conquistadores, nos escravizadores. Os seles, cuja guerra de 1917 se narra no segmento "Os olhos", são as luzes do processo de independência, pois foi a sua revolta que mostrou o caminho: o de lutar por uma Angola inteira e não somente por suas terras. Os seles são "Os olhos" da nação-corpo-narração de Pepetela, por isso 
também chamados ao 1975 para cortar os fios de arame que cercavam as terras, antes deles, que os donos dos impérios haviam roubado em 1917. É importante notar que são todos congregados pelo MPLA para fazer realizar a "chuva de lavar rancores."

A luta nacional foi ganhando um caráter de luta de classes, os "donos dos impérios" angolanos - formados às custas da exploração da terra e de seu povo - foram considerados inimigos dessa nação. Eram os continuadores da opressão colonial secular. A estátua Yaka, narradora também do fragmento abaixo, diz quem é quem no processo revolucionário.

Os senhores de império se insinuando nas conversas com outros recém-chegados, gordos e luzidios de festins ianques com ou sem gorro de leopardo (...) nos também lutamos (...) e os donos de império dizendo claro vocês é que lutaram (...) e estranhamente era verdade a luta deles tinha sido a mesma, mas os cuvales só tinham ouvido falar do movimento que chegou no avião da Zâmbia e diziam que iam derrubar o arame farpado das fazendas (...) e os Cunhamas idem e os Ngambos ibidem e os senhores de impérios iam falar com os do gorro de pele de leopardo (...) que o arame farpado era sagrado assim como a propriedade que ele simbolizava (...) e o arame foi mesmo cortado no meio das festas de matar boi e cabrito. Nas Mundas do Huambo o batuque durou três dias. (PEPETELA, 1985, p. 246).

As expressões "os do gorro de pele de leopardo" e "recém-chegados, gordos e luzidios de festins ianques" evidencia o apoio dos Estados Unidos, do Governo do Zaire, Nobutu, e de portugueses salazaristas ao FNLA, que "estranhamente" havia lutado na guerra anticolonial. Estranhamente, porque tal Frente parecia gostar mesmo era de "senhores de império". Mas os cuvales que já haviam cortado os arames, que cercavam as suas ex-terras, estavam em festa nas Mundas do Huambo. O 1975 é todo euforia. Nele se realiza a profecia da estátua Yaka: a Revolução. Cada vitória sobre os exércitos inimigos é comemorada na rua, com festa.

A violência é um dado marcante. A revolta latente, mas contida nos anos de opressão colonial, conforme Fanon (1979) veio à tona. O povo nas ruas, de arma em punho, estava a fazer justiça com as próprias mãos. Estava a vingar os seus sofrimentos: a escravatura, o trabalho forçado, a perda de suas terras, a dispersão de suas comunidades étnicas, a exploração, enfim... Tudo o que havia passado. Como diz Walter Benjamin (1989, p. 231), "era a oportunidade revolucionária de lutar por um passado oprimido."

É dessa experiência revolucionária que surge a nação no romance Yaka. Ela é filha do "estouro do trovão", que foi chamando "os orvalhos e chuviscos" e, depois, "as nuvens antes dispersas, do Norte, do Sul, do Planalto dos ovimbundos e do Leste". Estas nuvens desaguaram em uma "torrencial tempestade". E assim, como a nação, que se vai construindo simbolicamente das várias lutas, só se realiza plenamente em 1975, no segmento "As pernas", o romance Yaka só será completo, a partir da articulação dos seus cinco segmentos, onde se narram as lutas, num mecanismo de interação entre o processo de luta do povo angolano pela autodeterminação, e o processo de escritura do próprio texto. 
Por tal processo de escritura se vai delineando um corpo, que vai ganhando forma, que vai ganhando vida ao ir utilizando as suas partes principais: "A boca", "Os olhos", "O coração", "O sexo" e "As pernas". Um corpo de criança e seu processo de maturação. Uma criança indefesa e insegura que, de início, ousa as primeiras palavra, mas que, aos poucos, começa a olhar ao seu redor e a interpretar o visto, para, em seguida, elabora seus pontos de vista, suas posições. Com o tempo vem a puberdade, o sexo, a perda da inocência e a necessidade de se afirmar enquanto ser, para, com a maturidade, com as próprias "pernas" e já com as outras partes articuladas: "boca", "olhos", "coração" e "sexo", traçar o seu destino, a sua autonomia.

\section{O ENGENHO E A ARTE DE PEPETELA}

A história como o romance seleciona, simplifica, organiza, faz resumir um século numa página e esta síntese da narrativa não é menos espontânea do que a da nossa memória. (Paul Veyne, 1987, p. 16)

Recuperar a memória do que se denominou nação angolana é o que Pepetela também realiza em Yaka. A própria organização do texto em capítulos, cujas datas nos remetem às principais lutas de resistência do povo angolano contra o colonialismo, já sugerem um olhar diferenciado do autor em relação à versão oficial da história da nacionalidade.

Aliás, como observa Said (1995, p. 34), “a maneira como formulamos ou representamos o passado molda a nossa compreensão e nossas concepções do presente." Nesse sentido, o autor utiliza-se do passado de lutas como estratégia de intervenção no presente, já que é exatamente nesse presente (o da enunciação) que reside o processo de transição da sociedade angolana colonial para a sociedade pós-colonial.

O ano de 1975, como já foi dito, fecha o romance Yaka e também a era do colonialismo em Angola. Para falar desse ano de emancipação da nação angolana - nação, em forma de sonho e desejo, narrada, desde o final do século XIX, no romance - faz-se necessário também abordar as conturbações políticas e econômicas vividas por Portugal por causa dos quatorze anos de guerra colonial contra os movimentos armados de Angola, Moçambique e Guiné Bissau. Com exceção desse último país, até 1975 as guerrilhas não haviam conseguido subtrair, por completo, os territórios colonizados ao domínio luso, mas obrigavam as autoridades portuguesas a manterem em África enormes contingentes militares e a arcarem com despesas que absorviam grande parte dos recursos nacionais.

O tema dominante da oposição ao regime totalitário implantado por Salazar, que já durava então quase quarenta anos, passou a ser o protesto contra a guerra. Observa José Hermano Saraiva (1984, p. 365) que "a política ultramarina, ideal nacional que ajudara a nascer a Primeira República, transformara-se num tema político, que iria fazer naufragar a Segunda”. Em 25 de Abril de 1974, um movimento das forças armadas derruba o regime e marca o inicio da Terceira República Portuguesa.

Com essa mudança de rumo na história lusitana, ainda seguindo Saraiva (1984), consumaram-se decisões e opções que implicaram, dentre outras coisas, a descolonização das "Províncias Ultramarinas" (era assim 
que as autoridades do Estado Novo chamavam as colônias). Após o 25 de Abril, os três movimentos de libertação de Angola - MPLA, FNLA E UNITA - continuaram pressionando o novo governo português, que se posicionou favorável à independência desde que fosse implantado em Angola um governo transitório, nos moldes de uma democracia pluralista-representativa, no qual os três movimentos e Portugal dividiriam o poder. Em janeiro de 1975 é firmado o Acordo de Alvor, que marca a independência para 11 de novembro do mesmo ano.

Com o citado Acordo, a guerra anticolonialista chega ao fim, porém tem inicio o período de guerra civil, isto porque os três movimentos, com propostas políticas e orientações ideológicas bem diferentes, tentam legitimar-se no poder. Por isso, como aponta uma das personagens do romance, a guerra se faz inevitável. "Em Luanda, o MPLA expulsou os outros dois, vai terminar o governo de transição. A FNLA tomou conta do Norte. A UNITA do Bié. No Lobito já houve tiros." (PEPETELA, 1985, p. 257)

O quinto segmento do romance "As pernas - 1975" trata dessa guerra, que não se restringiu apenas às fronteiras do país. Estrategicamente Angola se encontra em uma das áreas de maior importância do planeta, a África Austral. Assim, interesses políticos e econômicos fazem com que governos de outros países interfiram no conflito interno, acirrando o enfrentamento bélico entre os grupos existentes.

Os Estados Unidos e o Zaire ajudam o FNLA, de Holden Roberto, a se manter no Norte Angolano, e até mesmo a dividir o Sul com a UNITA, de Jonas Savimbi. Os colonizadores angolanos, que não concordavam com a independência e também os militares do exército colonial salazarista (que combateram as guerrilhas angolanas desde 1961) se aliam à FNLA. Já a UNITA recebia o apoio direto do governo (na época racista) da África do Sul. Este país fazia fronteira com o território angolano ocupado por Savimbi. O MPLA tinha o apoio da antiga União Soviética e de Cuba e também recebia uma grande solidariedade de organizações políticas de países do Terceiro Mundo que, naquele momento, também lutavam contra as ditaduras militares de seus países, como é o caso do Brasil.

Na verdade, a guerra angolana estava no meio da guerra fria. De um lado, a antiga União Soviética; de outro, os Estados Unidos. As forças internas também se definiam por esses dois parâmetros ideológicos. Tanto é assim que, com a intensificação dos combates e com as vitórias paulatinas do movimento liderado por Agostinho Neto, o MPLA, os dois outros grupos, que não tinham divergências, do ponto de vista programático, acabaram-se unindo política e militarmente contra o MPLA. Este último movimento, assim que tomou Luanda, principal cidade angolana, criou as FAPLAS (Forças Armadas Populares de Libertação de Angola) e fez da referida cidade sede de governo da República Popular de Angola.

Holden Roberto e Jonas Savimbi, quando ainda controlavam o Sul e parte do Norte, criaram a República Democrática de Angola, com sede na cidade do Huambo, partindo o território, antes único, em dois. Tal "república" não teve muita duração, pois as FAPLAS, depois de submeterem totalmente o norte - o último reduto de Holden era o Ambriz - tomaram a cidade do Huambo, esvaziando bastante o poder de Jonas Savimbi, no Sul. 
Do ponto de vista ideológico, os narradores do romance, principalmente a estátua Yaka, que profetiza desde o inicio da narrativa a libertação total de Angola, através da metáfora da "chuva de música", não escondem as suas simpatias pelo MPLA, talvez porque esse movimento (de cariz socialista) não tivesse só a proposta de promover a independência de Angola, mas também libertar os angolanos da opressão social que marcou as suas vidas desde o momento que os colonizadores puseram os seus brancos pés na África negra.

Tais ideais, na prática, levaram à identificação do colonizador português como duplo inimigo: o invasor estrangeiro e o explorador da força de trabalho do povo autóctone. Os ex-colonos, na ocasião da guerra, já se haviam transformado em homens ricos de Angola (como o personagem Bartolomeu Espinha, genro de Alexandre Semedo) e não apoiavam Agostinho Neto, preferindo Holden Roberto. Também altos escalões militares apoiavam a FNLA.

Os narradores do romance identificam a Frente de Holden Roberto e a UNITA, de Jonas Savimbi, com os dominadores seculares de Angola. É bom deixar claro que o presente trabalho, assim como o texto de Pepetela, não ultrapassa o ano de 1975. O romance termina com a estátua Yaka dizendo a Alexandre Semedo que as FAPLAS - nas quais Joel, bisneto de Alexandre, já havia ingressado - ocupariam Benguela, libertando-a do poder da UNITA e da FNLA e, consumando, deste modo, a vitória da revolução em Angola.

São personagens-narradores como Alexandre Semedo e a estátua Yaka, cujas atuações atravessam a narrativa do inicio ao fim, que se encarregam de puxar o fio da história colonial e trazê-la até 1975, ano da independência. São gestos como os do Soba do Bailundo, Mutu-ya-kevela (PEPETELA, 1985, p. 45), e de Vilonda, Soba Cuvale (PEPETELA, 1985, p. 187), que morreram defendendo os valores e as tradições de seus povos que fazem com que o romance Yaka seja uma versão possível da história oficial angolana passada a limpo. Desta forma, as intervenções de personagens míticas - como é o caso da estátua Yaka, ícone maior do romance e sua metáfora, e toda a simbologia que do nascimento de Alexandre Semedo e dos gestos dos sobas emanam - podem ser lidas como filtros transcodificadores, por onde a história oficial será passada e alterada. Tais elementos míticos são peças-chave no urdimento na narrativa-nação de Pepetela.

Por outro lado, a presença dessas personagens míticas - por causa exatamente da inversão que provoca na história das fontes - significa uma veemente critica ao historicismo que se contenta simplesmente em estabelecer um nexo causal entre os vários momentos da história, através de um procedimento aditivo, conservando a "eterna" imagem do passado, que, como argumenta Walter Benjamin (1989), tem privilegiado tradicionalmente os dominadores.

O romance Yaka se realiza numa perspectiva inversa a esse conceito de historia, no que tange à empatia com os dominadores, justamente porque conta uma história de dominadores que se foram conscientizando de sua condição e resolveram lutar para mudar os seus destinos. Nesse caso, e ainda de acordo com Benjamin (1989), a tristeza que normalmente acomete o historiador ao apropriar-se da imagem do passado não atinge totalmente os narradores do romance, que renunciam a desfiar os aconte- 
cimentos como contas de um rosário. Se assim o fizessem, a tristeza destes narradores seria incomensurável, porque é difícil medir o tamanho do abuso e da violência praticados pelos colonizadores contra o povo angolano. Mas a grande preocupação dos enunciadores do romance, e isso já o dissemos, é com o presente e não simplesmente com o passado pelo passado.

Presente este, utopicamente construído com a "chuva de música" (com a revolução), cujas "nuvens" começaram a se formar a partir de 1890, ano de início da narrativa e, historicamente, quando se inicia a ocupação do interior do país pelo governo português. Pode-se dizer que a transcodificação dos eventos históricos selecionados por Pepetela na composição da obra é "luta escrita" do colonizado, que se organiza nos segmentos, formando um corpo que pode ser o texto ou a nação. Um corpo que poderá ser melhor entendido do ponto de vista do imaginário africano, uma vez que é, também, voz escrita, como diria Laura Padilha (1995), porque é o lugar de onde o colonizado fala.

\section{REFERÊNCIAS BIBLIOGRÁFICAS}

ANDERSON, Benedict. Nação e Consciência Nacional. Trad. de Lólio Lourenço de Oliveira. São Paulo: Ática, 1989.

BENJAMIN, Walter. Obras Escolhidas, v. I: Magia e técnica/arte e política. Trad. De Sérgio Paulo Rouanet. São Paulo: Brasiliense, 1989.

BHABHA, Homi (Ed.) Nação e Narração. Trad. de Glória Maria de Mello Carvalho. Belo Horizonte: Puc/MG, 1995 (Texto policopiado).

FANON, Frantz. Os Condenados da Terra. Rio de Janeiro: Civilização Brasileira, 1979.

HOBSBAWN, Eric J.. Nações e Nacionalismos desde 1780. Trad. de Maria Célia Paoli e Anna Maria Quirino. São Paulo: Paz e Terra, 1991.

PADILHA, Laura Cavalcante. Entre Voz e Letra: o lugar da ancestralidade na ficção angolana do século XX (tese de doutorado), Rio de Janeiro, Faculdade de Letras/UFRJ, 1995.

PÉLISSIER, RENÈ. História das Campanhas de Angola. Vol. I e II. Lisboa: Editorial Estampa, 1986.

PEPETELA, (PESTANA, Arthur). Yaka. São Paulo: Ática, 1985.

SAID, Edward W. Cultura e Imperialismo. Trad. de Denise Bottman. São Paulo: Companhia das Letras. 1995.

SARAIVA, José Hermano. História Concisa de Portugal. Lisboa: Europa - América, 1984.

TORRES, Alexandre Pinheiro. "Yaka (ou o calcanhar de Aquiles?)". In Literaturas Africanas de Língua Portuguesa. Lisboa: Fund. Calouste Culbeikian, 1987, pp. 197-203.

VEYNE, Paul. Como se Escreve a História. Trad. de Antonio José da S. Moreira. Lisboa: Edições 70, 1987. 